\title{
VALIDATED SPECTROPHOTOMETRIC METHOD FOR DETERMINATION OF TACROLIMUS IN MARKETED FORMULATION
}

\author{
Amardeep*, Mukunda S. Bande, Shilpi Agarwal \\ Assistant Professor, College of Pharmacy, University of Health Sciences, Rohtak, Haryana.
}

\begin{abstract}
A simple, rapid and sensitive spectrophotometric method was developed for the determination of tacrolimus in pharmaceutical dosage forms. Tacrolimus on dehydration with sulphuric acid resulted in the induction of $\alpha, \beta$ unsaturated enone system and $\lambda_{\max }$ value was observed to be $291 \mathrm{~nm}$. The calibration curve was linear in the concentration range of 10 $70 \mu \mathrm{g} \mathrm{mL}^{-1}$ for the sulphuric acid method $\left(\mathrm{r}^{2}=0.999\right)$ and the prepared samples were stable for a period of five days.

The proposed method was applied for determination of Tacrolimus in capsule dosage forms. The application of this simple method to routine quality control analysis of pharmaceuticals could contribute to their safety and therapeutic efficacy.
\end{abstract}

Keywords: Tacrolimus; sulphuric acid method; UV spectrophotometry; quality control

\section{INTRODUCTION}

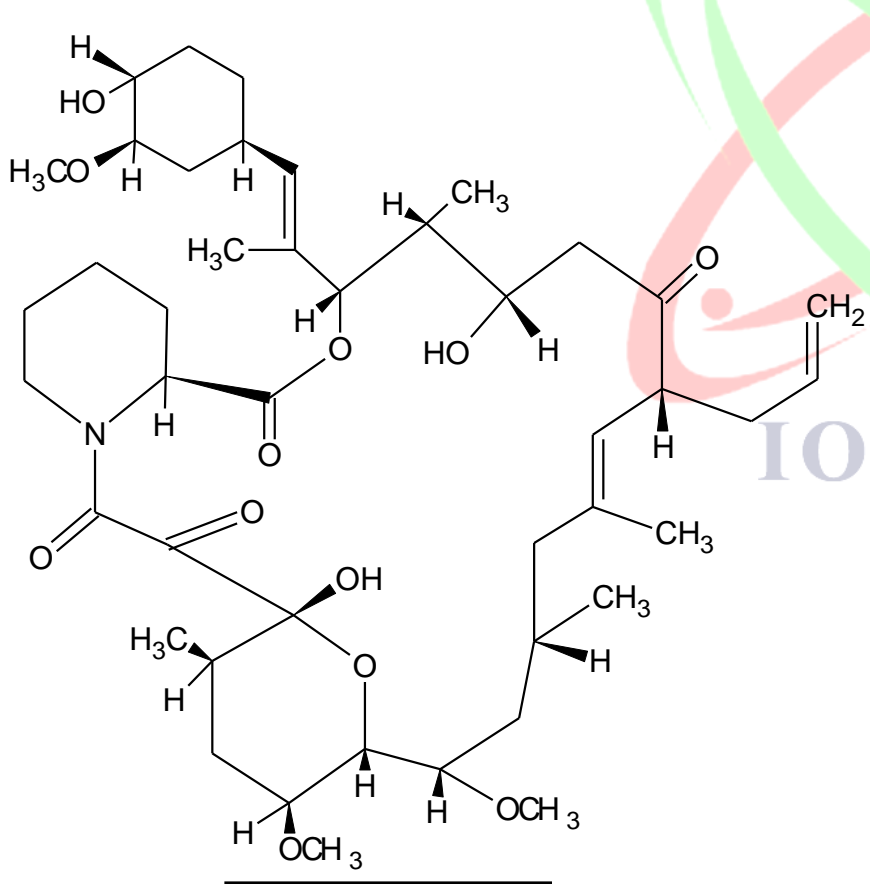

Tacrolimus is a 23-membered macrolide lactone with alpha, beta-diacetamide hemiacetal incorporated in the ring structure, as shown in Figure. Tacrolimus is reported to possess potent immunosuppressive activity and is extracted from "Streptomyces tsukubaensis". It is used clinically in the prevention of organ transplant rejection. The drug is also used for the treatment of various skin diseases such as vitiligo, psoriasis, atopic dermatitis and eczema (T.M. Boer et al., 2008). It is insoluble in water, slightly soluble in

saturated hydrocarbons, and highly soluble in ethanol, methanol and acetonitrile (T. Kino et al., 1987). Tacrolimus acts by inhibiting the $\mathrm{T}$ - cell activation. Tacrolimus has lower nephrotoxicity and reversible neurotoxicity (S. C. Garcia et al., 2004) and it is 100 times more potent than cyclosporin A. It is available in different formulations such as capsules, sustained release formulation and ointments etc.

As reported earlier, Tacrolimus could be detected by dissolving drug in organic solvent and reacting it with sulphuric acid. Different solutions were prepared using acetonitrile as organic solvent. The prepared concentrations were stable for 10 minutes after addition of sulphuric acid (Boer et al., 2008). Stability was the main problem with

Fig. 1- Tacrolimus

reported method.

Thus the present study involves the modification of the earlier reported method with the aim of overcoming the stability problem.

Due to presence of weak chromophore group in tacrolimus, detection and quantification of tacrolimus by U.V. spectrophotometric method is not possible because tacrolimus absorbs $\lambda_{\max }$ value at $210 \mathrm{~nm}$. Dehydration caused by the 
addition of sulphuric acid improves the potency of chromophore in the molecule by the induction of $\alpha, \beta$ unsaturated enone system.

Tacrolimus was weighed $(100 \mathrm{mg})$ accurately and dissolved in acetonitrile. Concentrated sulphuric acid was added to the stock solution and then volume was made up with acetonitrile. After treating with sulphuric acid dehydration of the molecule took place which is shown in figure 2. Due to dehydration $\alpha, \beta$ unsaturated enone system was introduced in the molecule and $\lambda_{\max }$ was observed to be $291 \mathrm{~nm}$. Further dilutions were prepared with distilled water. The scheme is shown below in figure 2.
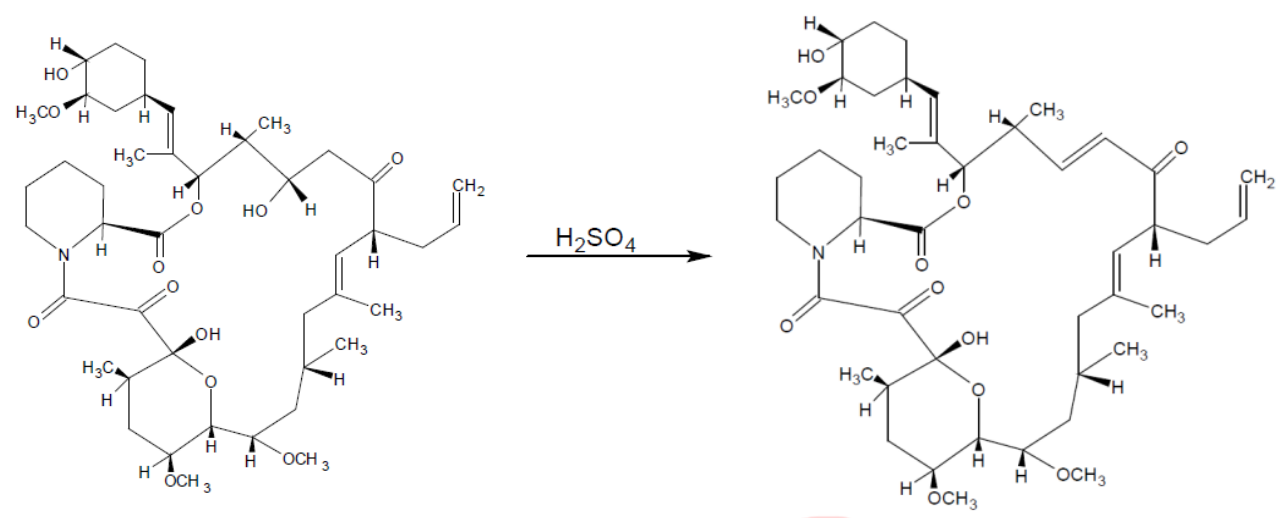

Fig. 2- Reaction showing dehydration and introduction of $\alpha-\beta$ unsaturated enone

The present method was developed for quantitative determination of tacrolimus in its dosage form.

\section{MATERIALS AND METHOD \\ Materials and reagents}

Tacrolimus drug was obtained from "Biocon pharmaceuticals, Banglore" as gift sample. Acetonitrile (HPLC grade) was purchased from "Merck specialties pvt. Ltd., Worli, Mumbai- 400018". Other chemicals were of analytical reagent grade. Distilled water was obtained from water purification system ELIX 03 (Millipore).

\section{Preparation of reference substance solution Preparation of "stock solution A"}

The stock solution was prepared by accurately weighing $100 \mathrm{mg}$ of Tacrolimus in a $50 \mathrm{ml}$ volumetric flask dissolved and diluted to volume with acetonitrile to obtain a concentration of $2 \mathrm{mg} / \mathrm{ml}(2000 \mu \mathrm{g} / \mathrm{ml})$.

\section{Preparation of "stock solution B"}

$0.5 \mathrm{ml}$ of solution was taken from stock solution A and $0.5 \mathrm{ml}$ of sulphuric acid was added in a $10 \mathrm{ml}$ volumetric flask and diluted to volume with distilled water to obtain a concentration of $100 \mu \mathrm{g} / \mathrm{ml}$.

\section{Validation of Method}

The developed method was validated using brand name "Pangraf" capsules nominally containing $1 \mathrm{mg}$ of tacrolimus (Pangraf), according to the label, by determining the following parameters: linearity, precision, accuracy, limit of detection (LOD) and limit of quantitation (LOQ), following the International Conference on Harmonisation (ICH Q2(R1) guidelines (ICH, 2005).

\section{Linearity}

Linearity was determined by constructing analytical curve, with six calibration points for tacrolimus with the concentrations $10,20,30,40,50$ and $60 \mu \mathrm{g} / \mathrm{ml}$. The absorbance values were plotted against respective concentrations of tacrolimus to obtain the analytical curve. The results were subjected to regression analysis by the least square method to calculate the calibration equation and correlation coefficient.

\section{Calibration curve}

The aliquots of working stock solution B were diluted with water to obtain the concentration range of $10-60 \mu \mathrm{g} / \mathrm{ml}$ for tacrolimus. The calibration plot was generated by replicate analysis $(n=6)$ of all the concentrations by measuring the 
absorbance at $291 \mathrm{~nm}$. Statistical parameters related to calibration curve like slope, intercept, co-efficient of correlation, standard deviation and relative standard deviation were determined.

\section{Accuracy}

Accuracy was determined by spiking a blank sample with the analyte at three different concentrations $(80 \%, 100 \%$ and $120 \%)$. Standard deviation of results was calculated and accuracy was determined in terms of \% recovery.

\section{Precision}

The precision of the method was determined by intra-day and inter-day precision. The intermediate precision of the method was assessed by carrying out the analysis on three different days (inter-days). Intraday precision was measured between three time intervals and interday precision was measured between three consecutive days. Three determinations for three concentrations covering the selected range were carried out. Precision was evaluated in terms of mean \% R.S.D. Percentage relative standard deviation was calculated.

\section{Limit of detection and limit of quantification}

Limit of detection (LOD) and limit of quantification (LOQ) were calculated by taking the replicate determination of blank. Calculation was done according to the equations.

$$
\begin{aligned}
& L O D=3.3 \times \mathrm{s} / \mathrm{m} \\
& L O Q=10 \times \mathrm{s} / \mathrm{m}
\end{aligned}
$$

Where $\mathrm{s}$ is the standard deviation of the absorbance of the sample and $\mathrm{m}$ is slope of corresponding calibration curve.

\section{Sample preparation}

To prepare the sample solution, 10 capsules of tacrolimus were individually weighed to obtain their mean weight and then an amount equivalent to $2 \mathrm{mg}$ tacrolimus was transferred to $10 \mathrm{ml}$ volumetric flask and volume made up with acetonitrile to obtain concentration of $200 \mu \mathrm{g} / \mathrm{ml}$. The solution was filtered and $5 \mathrm{ml}$ of filtrate was taken in a $10 \mathrm{ml}$ volumetric flask. To this $5 \mathrm{ml}$ filtrate $0.5 \mathrm{ml}$ of sulphuric acid was added and dilution was done using acetonitrile up to mark to obtain a concentration of $100 \mu \mathrm{g} / \mathrm{ml}$.

\section{RESULT AND DISCUSSION}

The absorption spectrum showed highest absorbance at $291 \mathrm{~nm}$, after the treatment with concentrated sulphuric acid and it was selected for the analytical studies, as shown in Figure 3.

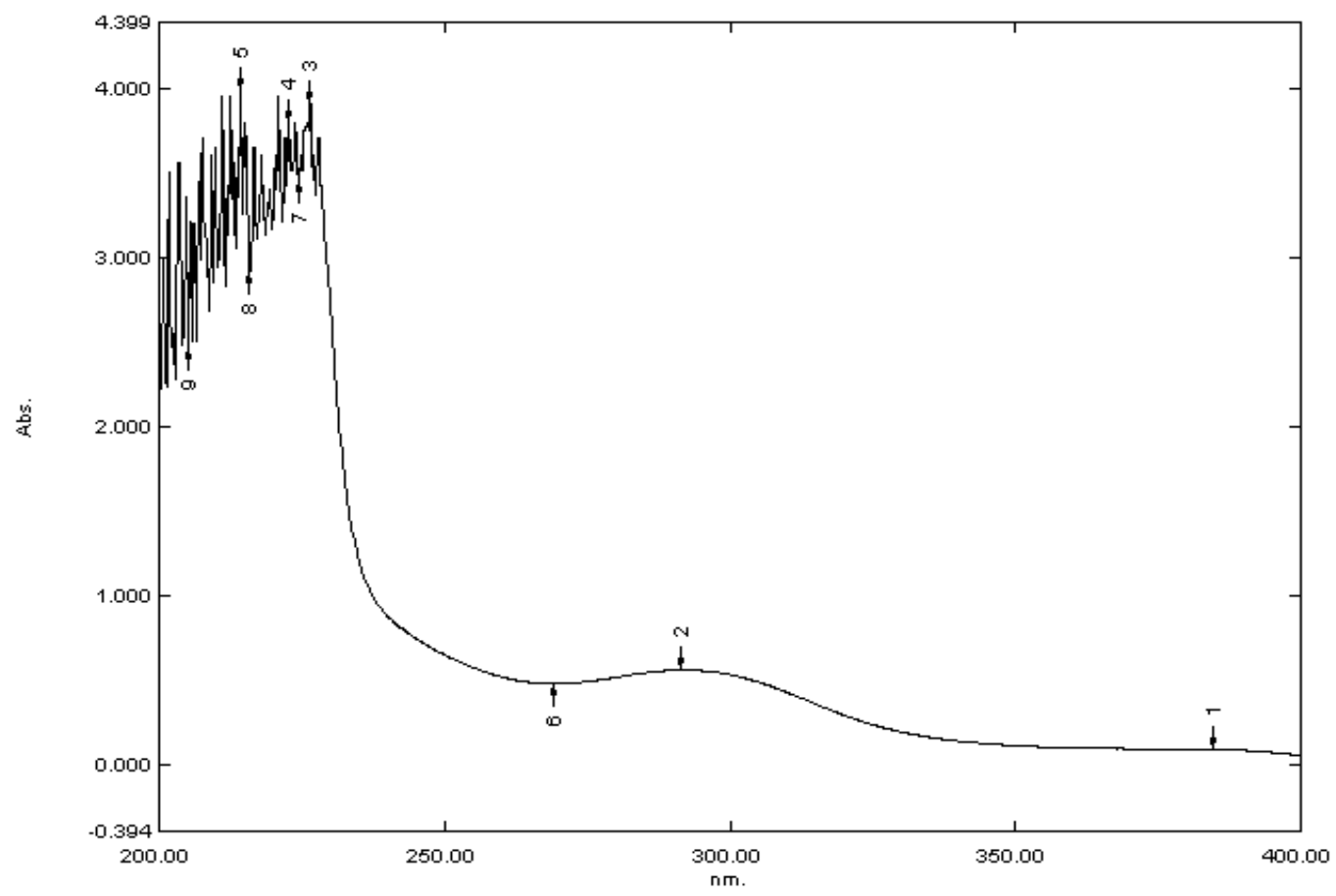


Fig. 3- Spectrum showing $\lambda_{\text {max }}$ at $291 \mathrm{~nm}$

\section{Optimization of reacting conditions}

The reaction was optimized by adding several volumes of sulphuric acid, from 100 to $500 \mu \mathrm{L}$, to the tacrolimus solution, and measuring the absorbances at various times. The maximum absorbance was achieved with $400 \mu \mathrm{L}$ of sulphuric acid.

\section{Analytical data}

Under the optimized analytical conditions, the optical characteristics and the statistical parameters for the proposed method are summarized in the Table - 1. An investigation of the intercept, slope, correlation coefficient and linearity suggests the excellent linearity of the calibration graph. Detection limit and slope indicates good sensitivity of the proposed method. The precision studies of the proposed method were done by carrying out 15 independent determinations at 3 concentration levels. The relative standard deviations were calculated and are shown in Table No. - 1 For additional confirmation of accuracy of the proposed method, standard addition method was performed by adding a known amount of pure drug to the dosage form. The result is summarized in table - 2 and considered to be very satisfactory.

The validated method was applied for the determination of tacrolimus in capsules. Ten capsules were assayed and results are shown in table - 2 .

\begin{tabular}{|l|l|l|}
\hline S. No. & Parameters & Result \\
\hline 1 & Absorption maxima $(\mathrm{nm})$ & 291 \\
\hline 2 & Linearity range $(\mu \mathrm{g} / \mathrm{ml})$ & $10-70$ \\
\hline 3 & Standard regression equation & $\mathrm{y}=0.010 \mathrm{x}-0.001$. \\
\hline 4 & Correlation coefficient $\left(\mathrm{r}^{2}\right)$ & 0.999 \\
\hline 5 & Accuracy $(\%$ recovery $\pm \mathrm{SD})$ & $99.56 \pm 1.99$ \\
\hline 6 & Precision $(\% \mathrm{RSD})$ & 0.7 (Intra - day) \\
\cline { 3 - 3 } & & $0.6($ Inter - day $)$ \\
\hline 7 & LOD $(\mu \mathrm{g} / \mathrm{ml})$ & 1.75 \\
\hline 8 & LOQ $(\mu \mathrm{g} / \mathrm{ml})$ & 5.13 \\
\hline
\end{tabular}

Table - 1 - Validation parameters

\begin{tabular}{|l|l|l|l|l|l|l|}
\hline Ingredient & $\begin{array}{l}\text { Capsule } \\
\text { amount } \\
(\mu \mathrm{g} / \mathrm{ml})\end{array}$ & $\begin{array}{l}\text { Level of } \\
\text { addition }(\%)\end{array}$ & $\begin{array}{l}\text { Amount } \\
\text { added }(\mu \mathrm{g} / \\
\mathrm{ml})\end{array}$ & $\begin{array}{l}\text { Drug found } \\
(\mu \mathrm{g} / \mathrm{ml})\end{array}$ & $\%$ recovery & $\begin{array}{l}\text { Average \% } \\
\text { recovery }\end{array}$ \\
\hline \multirow{3}{*}{ Tacrolimus } & 20 & 0 & 0 & 20.6 & 103 & - \\
\cline { 2 - 6 } & 20 & 80 & 16 & 36.9 & 101.87 & \multirow{2}{*}{$99.56 \pm 1.99$} \\
\cline { 2 - 6 } & 20 & 100 & 20 & 40.3 & 98.5 & \\
\cline { 2 - 6 } & 20 & 120 & 24 & 44.2 & 98.3 & \\
\hline
\end{tabular}

Table - 2 - Determination of accuracy by percentage recovery method

\section{Stability studies}

Stability studies were carried out using the working concentration in duplicate at room temperature and cool temperature and taking their absorbance in triplicate up to five days simultaneously. The percentage relative standard deviation was calculated and found to be $2.25 \%-3.62 \%$. The working concentration at cold temperature was found to be more stable. Data is shown in Table - 3.

\begin{tabular}{|l|l|l|}
\hline S. No. & Storage condition & R.S.D. (\%) \\
\hline 1 & Room temperature & 3.62 \\
\hline 2 & Cool temperature & 2.25 \\
\hline
\end{tabular}


Table - 3 - percentage relative standard deviation at different temperatures

\section{CONCLUSION}

The method was developed successfully within concentration range of $10-70 \mu \mathrm{g} / \mathrm{ml}$. the correlation coefficient value was found to be 0.999 and method was validated as per ICH guidelines. The validated method is found to be applicable for determination of tacrolimus in capsule dosage form.

As per the developed method, the drug was solubilised in organic solvent and volume was made up with water, thus the method was economical and solvent loss was negligible. The method was stable for five days. Thus the present method offers greater stability than the conventional method.

\section{REFERENCES}

1. Boer TM, Marques MR, Cardoso SG. Determination of tacrolimus in pharmaceutical formulations by validated spectrophotometric methods. J Basic and Applied Pharmaceutical Sciences, 2008; 29(2):137-143.

2. Kino T, Hatanaka H, Hashimoto M et al. FK506, a novel immunosuppressant isolated from a Streptomyces. I. Fermentation, isolation, and physicochemical and biological characteristics. J Antibiot, 1987; 40:1249-1255.

3. Goto T, Kino T, Hatanaka H et al. FK506, historical perspectives" Transplant Proc 1991; 23:2713-7.

4. Garcia SC, Lopes LS, Schott KL et al. Ciclosporina A e tacrolimus: uma revisao", J Bras Patol Med Lab 2004; 40:393-401.

5. ICH. International Conference on Harmonization of Technical Requirements for the Registration of Pharmaceutical for Human Use. "Validation of analytical procedures: text and methodology Q2 (RI); 2005 November; Geneva, Switzerland. 1-13.

6. Taormina D, Abdallah HY, Venkataramanam R et al. Stability and sorption of FK 506 in 5\% dextrose injection and 0,9\% sodium choride injection in glass, polyvinyl chloride, and polyolefin containers. Am J Hosp Pharm 1992; 49:119-22. 